\title{
UNA LECTURA VERBAL ANTES QUE LITERARIA DE UN TEXTO POÉTICO: EL SINTAGMA SIN DUELO EN UNA ODA DE FRAY LUIS DE LEÓN
}

\author{
MARgherita MorREALE \\ Universidad de Padua
}

La escasa atención al español de la época del autor, talón de Aquiles en la lectura de los textos de antaño y en la evaluación de los testimonios, se manifiesta en la aproximación puramente "literaria" al texto, frente a otra más objetiva y fundada en el uso de la lengua. Éste es el caso de la 1 . $^{\text {a }}$ estrofa de la 2." oda a Felipe Ruiz de Fray Luis de León en los vv. 1-5, décima en los testimonios principales; en la edición del hispanista italiano Oreste Macrí de 1982, con su testimonio preferido, la prínceps de Quevedo, $1631(q)$, y el ms. perdido subyacente ' (y por tanto también de quienes le siguen, Alcina, Serés, Blecua y Cuevas ${ }^{2}$ ), suena:

¿Quándo será que pueda

libre d'esta prisión volar al cielo,

Felipe, y en la rueda

que huye más del suelo,

contemplar la verdad pura sin duelo? ${ }^{3}$

El testimonio del ms. llamado "Jovellanos" J (que prefiere el P. Vega), reza:

\footnotetext{
' Antes, en el ensayo "Sobre el texto crítico de las poesías de Fray Luis de León", Thesaurus. Boletín del Instituto Caro y Cuervo, 12, 1957, págs. 1-52, se había valido del pasaje para confirmar el carácter definitivo de "sin duelo" en q (vid. pág. 16).

2 Pero no separamos con (,) la oración de relativo (como en efecto no la separa el $P$. Vega en su edición).

${ }^{3}$ La estrofa es el digno exordio de una de las odas más comentadas por los editores de la poesía luisiana con referencia a antecedentes en Séneca, Boecio, Prudencio, y otros autores, incluido Benito Arias Montano, el amigo de Fray Luis.
}

$R F E, \mathrm{LXXX1}, 2001,3 .^{\circ}-4^{\circ}$, pags. $415-422$ 
¿Quándo será que pueda

.................

contemplar la verdad pura, sin velo?

El pasaje implica, pues, una variante y la manera de evaluarla; aparte de nuestra preferencia inicial por la segunda de estas soluciones, que cuadra mejor con el verbo contemplar ${ }^{4}$, podemos prever que $\sin$ velo y $\sin$ duelo, en su función respectivamente secundaria y terciaria (v.i.), al no desempeñar el papel de rima nata, son más susceptibles de intercambio por obra de un recensor o copista.

Si se tratara de elegir entre velo y duelo, como hace Macrí, equiparando duelo sin más con dolor, y a su vez Alcina, con lat. malum, citando "omnis mali experti" del Comentario del Salmo xxvi del propio Fray Luis, habría que constatar que en la poesía luisiana abundan los dos por igual, y en muchos contextos son intercambiables, con duelo favorecido en poesía por la rima, y tanto en poesía como en prosa por las combinaciones rítmicas a las que se presta, como en el Libro de Job en tercetos, 16.40 "A mal añadió mal, a duelo duelo" 5 . Por otra parte, para explicar la interpretación de Macrí, duelo 'dolor', piénsese en los antecedentes literarios italianos del uso similar de duolo ${ }^{6}$, además de doglia y doglioso, en el mismo Petrarca, y también Bernardo Tasso y los petrarquistas del Cinquecento.

Pero aquí no hemos de partir de duelo sino de sin duelo como sintagma lexicalizado: el Diccionario académico s.v. lo acompaña con sin tasa: "sin duelo. loc. adv. sin tasa, sin escasez, abundantemente", y María Moliner desde la $1 .^{a}$ edición de su Diccionario de uso del español (Madrid, 1966), tras la prudente advertencia de 'poco usado', incluye la ejemplificación: "sin duelo, sin tasa o miramiento, "gastar (pegar) sin duelo", donde gastar, con la idea del dolor que suele acompañar el gasto, refleja la documentación más antigua, y definiciones como la del ya citado Correas: "gastar sin duelo, sin lástima de consumir los dineros y hacienda", pág. 694.

\footnotetext{
${ }^{4}$ Que en nuestra época tan poco contemplativa tal vez requiera una defínición; nos la ofrece Sebastián de Covarrubias en su Tesoro de la lengua castellana o española (1611), s.v: "considerar con mucha diligencia y levantamiento de espíritu las cosas altas y escondidas que enteramente no se puede percibir con los sentidos, como son las cosas celestiales y divinas".

5 También en los refranes, con el efecto de la combinación vocálica, e.g. en "Duelo ageno, de pelo cuelga"; cf. Gustavo Correas, Vocabulario de refranes y frases proverbiales. Texte établi. annote ef presenté. ed. de Louis Combe, Bordeaux, Institut des Études hispaniques, 195l, pág. 338, del que aquí citamos, normalizando la grafia, en sustitución de la edición anticuada e incompleta de la RAE, $1924^{2}$.

${ }^{6}$ Muy frecuente en el Canzoniere de Petrarca, donde duolo aparece 27 veces, proporcionalmente superior al del más corriente dolor(e), con 49.
} 
La documentación del sintagma es antigua, ya que se halla en Berceo, Milagros, 23. vv. 628ab, "Por exaltar su fama, el su precio crecer, / derramava sin duelo quanto podié aver ('obtener')"; y ello en relación con el 'gasto indoloro': véase en El Arcipreste de Talavera: "al pagar será el dolor" ${ }^{7}$, también aludiendo a los dolores que se atribuyen al pago ${ }^{8}$; con pegar, que hemos visto citado por María Moliner entre paréntesis, la lexicalización respecto a 'dolor', pasa posiblemente por la idea de 'sin compasión'.

El propio en Fray Luis nos brinda un antecedente en los tercetos aludidos del Libro de Job, "capítulo" 27.4-6:

Y dixo: - Vive el que mantiene el suelo, que tiene de amargor mi alma llena y sin juzgar me hiere tan sin duelo;

precedido en esto por numerosos ejemplos anteriores, como en un dezir de Francisco Imperial, que reproducimos del Cancionero de Baena, n. ${ }^{\circ} 601.60$ "firióme sin duelo la despiadada", y también en las obras dramáticas de Lucas Fernández: "Ilega, démosle sin duelo" .

Del Libro de Job en tercetos del que acabamos de citar, en el "capitulo" 40.19-21, se da otro pasaje ilustrativo de la evolución que perseguimos; alli, en rima, y posiblemente con una función adverbial reforzativa, en la lábil frontera entre el léxico y la sintaxis:

rompe de la arrogancia altiva el velo

y baxo de tus pies la pon sin duelo;

y ello como una de las muchas amplificaciones de la versión literal, que en Job 6 suena: "Esparze todo sobervio y confúndelos, y atiende a todo arrogante y abáxale".

En prosa y antepuesto al verbo recuerdo sin duelo del Dioscórides traducido y comentado por el Dr. Andrés Laguna, donde refuerza una invectiva contra los médicos, en sus recetas sobreabundantes e indiscriminadas:

\footnotetext{
${ }^{7}$ Alfonso Martinez de Toledo, El Arcipreste de Talavera o sea El Corbacho, 1.26, ed. Lesley B. Simpson, Berkeley, Univ de California, 1919, pág. 83; el pasaje palede localizarse en otras ediciones por medio de R. y L. S. de Gorog, Concordancias del "Arcipreste de Ta" lavera", Madrid, BRH, 1978.

${ }^{8}$ Sobre el dolor relacionado con el pago abundan los refranes; cf. Correas: "At comer "gaudeamus', al pagar 'ad te suspiramos"'; L. Martínez Klejser, en su Refranero general ideológico español, entre los n. ${ }^{05} 48.364-82$, cita el de 48.376 "Al comer, vita dulcedo, al pagar ad te suspiramus [ponemos en cursiva las palabras de la salve], $\mathrm{y}$ en el refrán que le sigue: "...al pagar sollozos y duelos".

${ }^{9}$ Cf. Farsas y Églogas, ed. Manuel Cañete, Madrid, Real Academia, 1867, pág. 156; en la edición de M." Josefa Canellada para "Clásicos Castalia", Madrid, 1976, sin comentario.
} 
Ansí que de los tales médicos no menos se deve huir que de la pestilencia, visto que de las confecciones y electuarios que no conocen, $\tan \sin$ duelo os arrojan onças y libras como si fuessen para echar en algibes ${ }^{10}$.

Aunque parece más frecuente que sin duelo modifique el verbo, también lo hallamos como modificación del sustantivo; p. ej., en ya mencionado $A r$ cipreste de Talavera:

Pues aguas rosadas e de azahar almizcadas, abundancia sin duelo (p. 9);

Duelo como afin a dolor, aparte de lijeras diferencias ${ }^{11}$, retrocedió ante éste, también por su polisemia respecto a 'luto' o 'solemnidad funeral' ${ }^{12}$; pervivió, en cambio, en el sintagma sin duelo: con gastar lo emplea Cristóbal Suárez de Figueroa en El Pasagero, Advertencias utilisimas a la vida humana (1617), cuando cuenta de los emolumentos que recababa el protagonista en las casas de juego; alli éste pondera la generosidad de los donantes con "Dase en estas partes sin duelo por salir de lo dudoso"13. Siglos más tarde, José de Zorrilla escribe: "Llora, rey, llora sin duelo" 14 .

Baste esta breve documentación de sin duelo para sustraernos a las ediciones de la Poesía de Fray Luis, y a sus eventuales comentarios: al de Macrí, con el recurso al 'campo semántico del gozo', y al de Alcina, que acepta la lectura de su predecesor; a saber:

sin duelo: es lectura de $q$ frente a 'sin velo' de la mayor parte de los manuscritos. Es sin duda una lectura más difícil;

${ }^{10} \mathrm{Cf}$. Pedacio Dioscórides Anarzabeo, acerca de la Materia medicinal y de los venenos mortiferos. Traduzido de la lengua Griega, e illustrado con claras y substanciales annotaciones, y con las figuras de innumerables plantas exquisitas y raras. por el Doctor Andrea de Laguna, Médico de Julio III Pont. Max. En Anvers, En casa de luan Latio, Anno MDLV. Com gratia et privilegio Imperiali; cf. Anotation, Lib 1, pág. 4.

${ }^{11}$ En los documentos recopilados en el Diccionario español de textos médicos antiguos, ed. M. ${ }^{\mathrm{A}}$. T. Herrera et al., Madrid, 1996, compárense la entrada duelo con la más extensa de dolor; aquél aparece alineado con cuidado y miedo como causa de enfermedad: "djxe Rufos que se fazen los anacrances [la gota o podagra] de cuidado e de miedo e de grant duelo" (s. Xv), "muchos homes (léase hombres) mueren súbitamente de gran duelo que se allega la calentura al coraçón tan fuertemente fasta que le afoga y muere" (1545); ello aparte del verbo doler y sus derivados, dolencia y doliente.

${ }^{12}$ Cf. entre otras muchas citas que podrían aducirse, El Conde Lucanor, donde en el capítulo 175 se lee: "fizo el Cid su confesión en la Iglesia de San Pedro de Vajencia, e mandó que.] urgiesen en su cuerpo con mirra, e después que fuese muerto, que no fiziessen por él duelo", ed. J. M. Blecua, Madrid, BRH, 1983, 2, pág. 173.

${ }^{13}$ Ed. M..2 Isabel López Bascuñana, Barcelona, Universidad, 1988, vol. 2, pág. 494.

${ }^{14}$ Cf. Obras, Madrid, 1887, vol. 1, pág. 93b. 
¿dificil para quién?, para nosotros o para los lectores de la época? El dictamen de Alcina de sin duelo como lectio difficilior, inaceptable para la ecdótica, interesa, en cambio, para la historia de la lengua, porque excluye el sintagma de la familiaridad siquiera pasiva de parte de los hablantes cultos; el terminus ad quem en la lengua de los doctos lo habia colocado yo a mediados de nuestro siglo ${ }^{15}$, pero el colega J. L. Rivarola me proporciona amablemente una cita de Viejas historias de Castilla la Vieja (1964, ed., 1969), donde Miguel Delibes, acorde al estilo del tema, escribe: "Madre se puso loca, y como en esas cosas, como es sabido, lo mejor son los golpes, entre las Mellizas y yo empezamos a propinarle sopapos sin duelo" pág. 48. Para años más recientes, mi breve encuesta entre personas leidas únicamente arrojó un vago recuerdo del estribillo de Garcilaso, Égl 1.70

salid sin duelo lágrimas corriendo.

Justamente de esta cita garcilasiana, que se combina como estribillo con las estrofas en las que Salicio en el "apartamiento del solitario monte" expresa su desesperación ante la dureza de la amada ${ }^{16}$, ha dado pie para una interpretación como la de Macrí, en sintonía con un razonamiento típico de literatos: Elias L. Rivers, por lo demás benemérito de los estudios de Literatura del Siglo de Oro, glosa el texto del modo siguiente (tras una densa rememoración del 'tópico de las lágrimas'):

Salid sin que os doláis [de mí, de vosotras (!?)], lágrimas corriendo ${ }^{17}$.

Es sintomático que otro crítico norteamericano, conocido por sus estudios de poesía cancioneril, P. N. Dunn, quien más citas de sin duelo ha manejado, en una nota que dedica justamente a muestro pasaje ${ }^{18}$, se cegara ante la afinidad con $\sin$ tasa ${ }^{19}$; pero esto se explica por la tendencia a interpretar la poesía lírica por lo que el crítico espera ${ }^{20}$.

\footnotetext{
15 Gracias al Archivo del Instituto de Lexicografia de la Real Academia, donde la documentación más reciente, y no limitada a sin duelo, es la del erudito Agustín González de Amezúa: "Cervantes hubo de aprovechar la larga ociosidad de una vida pueblerina para leer mucho, mucho, sin duelo ni descanso", en Cervantes creador de la novela corla española, Madrid, 1956, 1, pág. 44.

${ }^{16}$ Cf. Obras de Garcilasso de la Vega con anotaciones de Fernando de Herrera, Sevilla, 1980 , ed. fcs., Madrid, CSIC, 1973, respectivamente págs. 388 (con el estribillo repetido hasta la pág. 394), y pág. 416 para el comentario.

17 Cf. Garcilaso de la Vega, Obra completa, Madrid, 1981, págs. 271-72.

I8 Cf "Garcilaso's sin duelo", Modern Language Notes, 80, 1965, págs. 25I-58, en el que se basa Rivers para la defínición pleonástica (y fundamentalmente errónea) que hemos aducido.

${ }_{19}$ Durn, y con él Rivers, consideran la equiparación con sin tasa como "inventada para explicar el verso garcilasiano" (pero cf. Fray Luis en oda 18(13).30 “...y (se) lança (et alma)
} 
Los versos con que Fernando de Herrera comenta este pasaje reintroducen un contenido al parecer léxico, aunque también sujeto a lexicalización (y diferente del que sugiere Rivers); a saber:

Lágrimas de mi consuelo,

salid, salid $\sin$ recelo...;

en la glosa de Sa de Miranda,

corren lágrimas justas sin parar ${ }^{21}$,

el verbo parar en contexto negativo se corresponde con sin duelo, ya completamente lexicalizado como sin tasa.

Ponemos por último una opción adicional que afecta al ritmo y a la sintaxis: en la variante de $q$, sin duelo modificaría el verbo contemplar; 'contemplar sin tasa', 'sin fin', como 'para siempre, en la otra vida' ${ }^{22}$; "sin velo", en la lección que preferimos, también puede leerse como complemento del verbo, con el sentido propio de velo, que se da también en otros pasajes como 'obstáculo a la vista' ${ }^{23}$, especialmente de cosas superiores o celestiales ${ }^{24}$ ); también podría modificar el adjetivo puro, 'en toda su pureza', con lo que se relacionarian puro con "sin velo"; o podría funcionar junto a éste como una segunda especificación de verdad ${ }^{25}$; en esto varía el ritmo

en aquel bien libre de tasa", 'en un bien infinito'). También sin tasa requeriría una explicación histórica que DCECH, al subsumirlo s.v. táctico, no da. Pero lo ilustran las frases comer sin tasa, herir sin tasa, y la definición del Diccionario de Autoridades: "tasa. vale tarnbién medida, regla o dieta que se pone a alguno en la comida o porte o enfermedad o castigo".

${ }^{20} \mathrm{Y}$, en el caso específico, por el tópico de dirigirse el poeta a las lágrimas como seres animados; cf. Francisco de Figueroa 7.1-4 "Lágrimas que salis regando el seno / por vuestra antigua, ejercitada via, / seguras del temor justo que había / a vos y a mis suspiros puesto el freno" (citado de Christopher Maurer, Obra y vida de $S$. de F", pág. 233. No en vano estos autores habían lejdo a Castiglione (o las fuentes neoplatónicas de éste) sobre el movimiento de los espiritus que hallan abiertas o cerradas las vias; cf. El Cortesano, ed. Madrid, 1942, págs. 86-87. Véanse además los antecedentes italianos y cancioneriles sobre ed llanto en $\mathrm{Bu}$ lletin hispanique, 9, 1958, págs. 505-07.

${ }^{21}$ Citado por J. M. Blecua en su edición de Garcilaso de la Vega, Poesias, Madrid, Clásicos Ebro, s.d., y antes por H. Keniston, Garcilaso de la Vega: A Critical Study of his Life and Works, Nueva York, 1922, pág. 151.

${ }^{22}$ Podría verse desarrollado el sintagma en oda 8.73-74 "clarísima luz pura, / que jamás anochece".

${ }^{23}$ Como en la Exposición de Job 6:21, donde se habla de "la llaga de su apocado temor", que los falsos amigos pretendian cubrir, y a que él (Job) "le quita el falso velo".

${ }^{24}$ Como en oda 17(14).31-32 "En ti (sierra), casi dessudo / d'este corporal velo..." (piénsese en "lo corporeo velo" de Petrarca, can 264.114 ).

${ }^{25}$ La modifícación del sustartivo con puro apunta hacia la esencialidad del nombre modificado: 1.49 "una fontana pura", 8.73 "clarisima luz pura", 10.42 "dolor puro", $21(20) .78(73)$ "con fe y voluntad pura" (como afin en estos usos a verdadero). 
con apoyo en $6 .^{a}$ ante cesura, o en $7 .^{a}$, aunque no necesariamente la puntuación, si se escatima la (,) como debería hacerse en poesía, incluso entre los eventuales atributos asindéticos ${ }^{26}$.

La modificación, más frecuente del verbo, hace que postulemos la primera alternativa; la segunda si $\sin$ duelo modifica el sustantivo (y es asimilable a sintagmas totalmente lexicalizados, cuales en la poesia de Fray Luis, 4.21. 6.84 sin cuento, $12.20 \sin$ fin, 17[15].25 sin error ${ }^{27}$ ). La frecuencia de la modificación del sustantivo con puro, en 1.49 "una fontana pura", 8.73 "clarisima luz pura", 21(20).78(73) "con fe y voluntad pura", Jobter 10.41-42 qué he sacado / más de mi ser amargo, y dolor puro?", incluso como artificio formal, en 15(17).53 "levanta al puro sol las manos puras", podría inclinar hacia la solución con pausa entre esticos.

La continuidad de la lengua castellana, mucho mayor que en otras románicas, como el francés, obsta a veces a la comprensión de los textos, que puede ser ilusoria, como aquí, y más en textos medievales ${ }^{28}$ : pero no hay que dejarse llevar por coincidencias parciales con el uso actual ${ }^{29}$; por otra

\footnotetext{
${ }^{26}$ Todos concuerdan en poner (,) entre más de dos atributos, como en Fray Luis, oda 1.27 "un día puro, alegre, libre quiero", 12.51-52 "zno ves el pecho / desnudo, flaco, abierto"; pero las ediciones se apartan, cuando entre los dos adjetivos media una diferencia morfológica, como en 3.15 "la belleza caduca (,) engañadora", o en 17(14).60 "contra un abismo immenso (,) embravecido", y cuando podría haber una jerarquización, como en 1.84 "al son dulce acordado", como "dulcemente acordado'; y en pasajes donde los adjetivos pueden incidir de distinto modo en el sustantivo, como en 8.32 "aqueșta celestial eterna esfera" ("esta esfera celestial, que es eterna"); y también, podría omitirse la (,) entre dos atributos, como se hace en las ediciones italianas, véanse las de Petrarca, cuando la asíndesis es estilístíca, como en [9(18).2 "en este valle hondo (,) oscuro", y en ib. 17-18 " ¿... quién concierto / al viento fiero (,) airado?", aunque sean transformaciones del tipo sindético que la poesía tiene en común con la prosa, como en 12.10 "y contra sí se muestra cruel y fiero" (v. q. Garcilaso, Égl 1.367 "tenebrosa [,] escura", pero también 2.100 "cansado y afligido"). Habria de hacerse pausa entre $\sin$ velo y el otro atributo puro pero no necesariamente con (,).

${ }^{27}$ En los romanceamientos bíblicos del s. XIII, como Esc I.1.6, Eclo $4: 34$ sin pro <- inutilis, sin sentido <- indoctus, ib. sin coraçón <- excors, 16:20 sin seso, 19:21 "ombre sin saber e sin seso" < - "homo qui minuitur sapientia et deficiens sensu": también se observan hoy como tendencia en la lengua coloquial, como con $\sin$ tregua, y con la prep. a, a tope.

${ }^{28}$ Lo ejemplifiqué en varias reseñas, y últimamente sobre el textos cancioneriles en "El Texto como fin y la Filologia como medio (en la propuesta Universitaria)" en Studia Hispanica Medievalia $I V$, Actas de las $V$ Jornadas Internacionales de Literatura Española Medieval, Buenos Aires, Repuiblica Argentina, Agosto 21-23, 1996, Buenos Aires, Pontificia Universidad Católica Argentina, Facultad de Filosofia y Letras, págs. 16-33, y en "Importancia relativa del estudio de la lengua y de la ecdótica para la lectura del Libro de Juan Ruiz", de próxima publicación en Los origenes del español y los grandes textos medievales: mio Cid. Buen Amor y Celestina, ed. Manuel Críado de Val para Biblioteca de Filologia Hispánica, Madrid, CSIC.

${ }^{29}$ Aunque en ese caso se comprende que desde la semántica de lós conceptos Macrí y Alcina se resistieran a deslexicalizar duelo, como afin a dolor, reduciéndolo a un instrumento gramatical, y más en un autor que tradujo por dos veces el Libro de Job; pero el uso es determinante.
} 
parte, la lingüística, con sus interpretaciones y sus terminologias innovadoras y cambiadizas, desaniman al estudioso de textos literarios; no obstante, una atención simplemente verbal, y la apropiación práctica de la lengua del autor son suficientes para evitar falsas interpretaciones como la que aquí hemos ilustrado.

Escritos de Fray Luis de León a los que nos referimos:

Manuscrito llamado "de Jovellanos": Biblioteca de la Academia de la Historia 9/2077, J.

Obras propias, y tradvciones latinas, griegas y italianas. Con la parafrasi de algunos Psalmos, y Capitulos de Job... sacadas de la librería de don Manuel Sarmiento de Mendoça, ed. Francisco de Quevedo Villegas, Madrid, 1631; ed. fes., Salamanca, Universidad, 1992, q.

Obras poéticas del maestro Fray Luis de León, vol. 1, ed. José Llobera, S.I., Madrid-Cuenca, 1932.

Poesías de Fray Luis de León, Edición critica, Prólogo de D. Ramón Menéndez Pidal. Epílogo de D. Dámaso Alonso, Madrid, 1955, citamos de la edición minor, Poesias originales. Traducción de las Églogas de Virgilio. Traducción de los Cantares de Salomón. Edición, introducción y notas de Angel Custorio Vega. O.S.A, Barcelona, 1980.

Poesías, ed. Oreste Macrí, Barcelona, 1982.

Poesia, ed. Juan Francisco Alcina, Madrid, 1986.

Poesia completa, ed. Guillermo Serés, Madrid, 1990.

Poesía completa, ed. José Manuel Blecua, Madrid, BRH, 1990.

Poesias completas, obras propias en castellano y latin y traducciones e imitaciones latinas, griegas, biblico-hebreas y romances, ed. Cristóbal Cuevas, Madrid, 1998.

Declaración del Salmo 26, Edición bilingüe. Texto latino fotostático. 1589. Traducción, edición y notas de J. M.” Becerra Hiraldo, Salamanca, Diputación, 1991.

Exposición del Libro de Job, ed. Javier San José Lera, Salamanca, 1992, 1, págs. 144-47. 